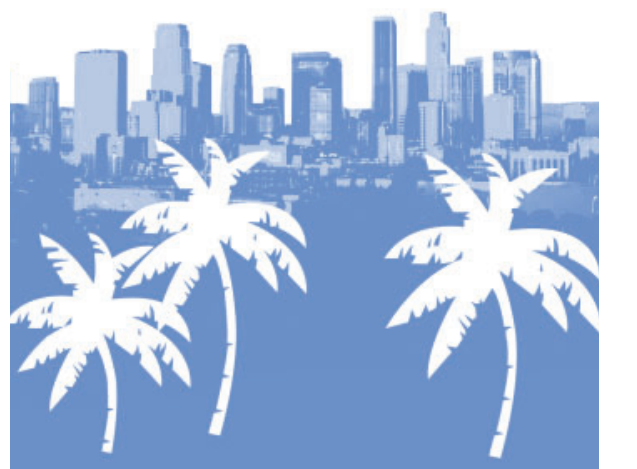

\title{
A Vision for the Arts in Los Angeles
}

\author{
Elizabeth H. Ondaatje and Kevin F. McCarthy
}

This paper captures recent discussions and new thinking about the future of the arts in Los Angeles, prompted in part by RAND research on 11 metropolitan regions and their arts sectors funded by the William Penn Foundation and the Greater Philadelphia Cultural Alliance. This paper was made possible by a grant from the Peter Norton Family Foundation.

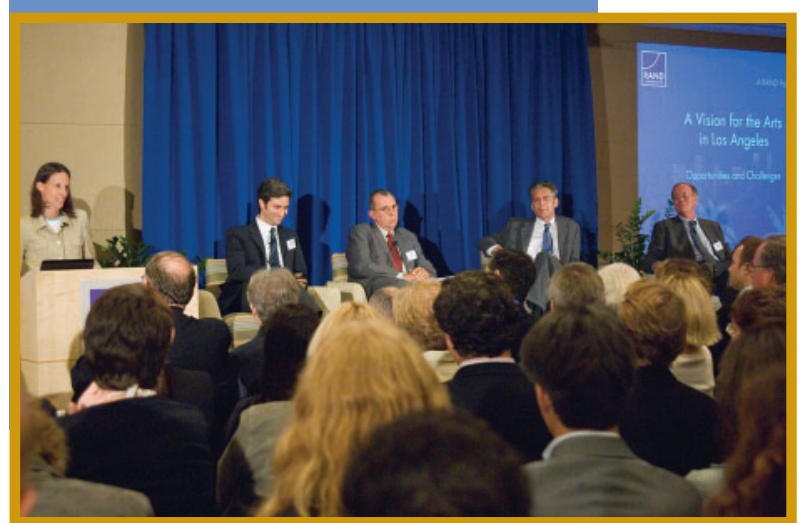

os Angeles is well-known as the center of film and television. But L.A.'s arts and cultural sector is much broader than the entertainment industry, and - it, too, is world-class. Moreover, it is poised on the threshold of an exciting new era. New directors, expansions of major institutions, critical attention, and tremendous artistic vitality have put Los Angeles in the arts headlines. A growing number of emerging artists and arts organizations live, work, and create throughout this multicultural metropolis. And further dramatic change lies ahead, arguably shifting the nation's center of gravity in symphonic music and contemporary visual art to the West Coast, creating an architecturally significant cultural district, and making Los Angeles not only a crucible of creativity but also a major attraction to the world's cultural tourists. The film and television entertainment sector adds many unique dimensions to the city's cultural landscape and it, too, is undergoing seismic shifts.

But do the city, the major players, the public, and even the arts sector itself have a vision for the arts in the next decade? Where do we want to go? What are the challenges and opportunities to getting there?

On October 5, 2006, the RAND Corporation hosted a Policy Forum to bring together local arts experts, artistic and cultural leaders, and RAND analysts to discuss the future of the arts in Los Angeles.

The timing was ideal. Now-while the arts in L.A. are growing and prospering-is the time for an informed debate and systematic new thinking about the future of the arts in L.A. The highly engaging Policy Forum, as well as a roundtable discussion with arts and civic leaders at RAND in November 2006, underscored both opportunities and challenges facing the arts in L.A.:

Postadolescence. Compared with other major arts centers, L.A. is younger by decades than those other arts capitals; one could say that L.A.'s cultural institutions are in their "postadolescence." And yet, L.A. already rivals them, artistically. In addition, the city is especially dynamic, culturally. Given future uncertainty, leaders in the arts and cultural sector would benefit if they considered strategic options; as a starting point, they need to identify where they want to go.

Civic pride. The arts community is passionate about L.A. and senses that the region is on a roll. But the energy and excitement in the arts community is not reflected in the public at large. The public doesn't necessarily appreciate or take pride in L.A.'s extraordinary cultural assets. And the lack of arts education in most of our public schools does not bode well for the next generation of artists, audiences, and supporters.

Ripe political climate. Los Angeles has an "arts mayor" for the first time in many years. Mayor Villaraigosa is a longtime arts enthusiast and supporter and, together with Olga Garay, his nominee to head the Department of Cultural Affairs, is committed to revamping the decades-old Master Cultural Plan. In addition, the county has boosted its investments in the arts, and various municipalities-Culver City, Hollywood, Santa Monica-have undertaken significant cultural development efforts. But it's unclear how all this energy should be channeled and where political leaders should put their efforts. 
Geography. L.A.'s vastness poses real challenges to collaboration, both perceptually (geographic spread leads some observers to compartmentalize the region rather than think of the entire region) and practically (congestion is an ongoing and worsening problem, and distances that would be considered reasonable in other metropolitan areas can take an unreasonably long time to travel). But that urban sprawl may also contribute to the diversity of local arts groups that spring up and provide opportunities at the community level.

Untapped resources. The entertainment industry has been a traditional strength in L.A., but the city has much more to offer in both the commercial and nonprofit arts. How do we leverage and build upon the presence of film, television, Internet, videogaming, and related industries as well as the actors, composers, programmers, writers, and designers that are a key feature of this city?

Diversity. In terms of organizations of different sizes, disciplines, missions, and artists working in many styles and stages of their careers, diversity is a great attribute of L.A.'s arts sector. Like a diversified economy, a diversified arts sector is a healthier arts sector. But it can also lead to fragmentation-and overcoming that requires greater collaboration and a common vision.

Policy Forum panelists recognized that these opportunities and challenges entail choices about where to direct attention and resources. How do we in Los Angeles make these choices? To make the most of L.A.'s tremendous artistic assets and unify its disparate elements, the arts community needs a vision of the future. A vision is the expression of our community's aspirations and goals, of how we see ourselves, and how we want to be perceived by others. Rooted in where we've been and where we are now, a vision guides decisions, investments, and energy in concerted action.

\section{The "Vision Thing"}

- A vision is an expression of the highest goals a community would like to achieve for itself.

- A vision for the arts is an ideal shared by community leaders and local citizens to express the image they would like to realize in the future.

- A vision provides a shared sense of identity and purpose that helps clarify and coordinate decisionmaking.

\section{What Are Alternative Visions for Los Angeles and Its Arts Community?}

\section{Here are three possibilities:}

1 Los Angeles as a world-class capital for arts and culture. This vision would place Los Angeles among London, Paris, and New York as top cities for the arts. World-class status is often defined by a city's flagship institutions, which take the lead in establishing the prestige, quality, and "star power" of the city's arts sector. With this vision, Los Angeles would position itself as a magnet for international cultural tourism. However, the major institutions exist within the larger arts ecology of the city; the feasibility of this vision depends on the overall climate for the arts in the city, which is also reflected in attendance, media coverage, and the viability of small and mid-sized arts organizations.

2 Los Angeles as a center of creativity. This vision would promote L.A. as a place that nurtures and supports artistic expression, innovation, and new work. Building on a firm foundation of artists, writers, filmmakers, and designers of all types (e.g., set, graphic, fashion, product), as well as higher education institutions that train artists, commission new work, and serve as research laboratories, Los Angeles would be a hub for those interested in producing and experiencing the cutting edge of arts and culture. This vision would also promote community involvement in creative activity as a hallmark of life here and might inspire the city to host a festival akin to the Venice Biennale with exhibitions of art, architecture, and film.

3 Los Angeles as a model of diversity through the arts. The arts in L.A. both reflect and celebrate the unique diversity of this metropolis. This ideal envisions the arts' weaving the social fabric by promoting a wide range of opportunities that both honor cultural differences and build bridges across social and economic divides. This vision is an expression of the desire for equal recognition and appreciation of all of L.A.'s art forms, particularly those represented in small groups-both amateur and professional. Inspired by this vision, artists and organizations of all types might collaborate on certain citywide themes-such as a "One City One Book" program, the Community of Angels Project, or any number of arts festivals. 


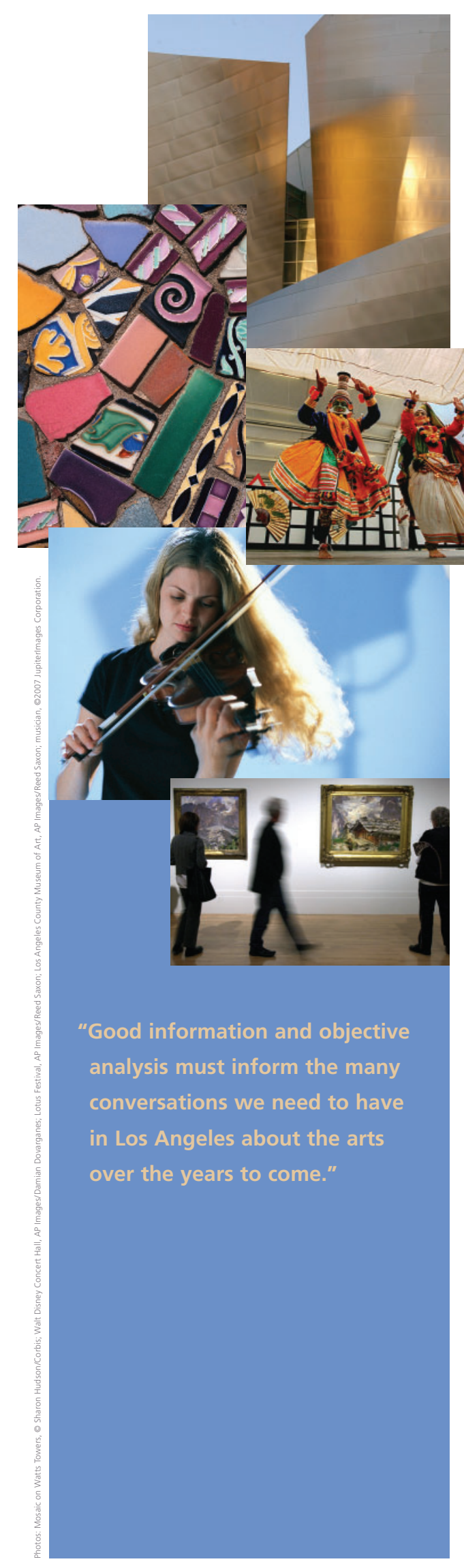

Although these visions are not mutually exclusive, they are distinct and imply different priorities and strategies. For example, pursuing a vision of a creative capital might emphasize affordable live/work space and festivals of new work by L.A. artists. Inspired by a vision of a world-class capital, we might promote L.A. artists in international venues (e.g., "Los Angeles 1955-1985: The Birth of an Art Capital," at Pompidou Center in Paris; Esa-Pekka Salonen conducting the London Symphony Orchestra) or ensure that great art is available here (e.g., through museum acquisitions or traveling exhibitions). Whatever it is, a common vision will allow arts and civic leaders to meet challenges more effectively. It not only helps transcend the issues or problems of the day, but it also serves as a reliable map for their resolution, to guide key actors in shaping and adapting to events. This sense of identity and purpose can be a powerful spur for collaboration and coordinated decisionmaking.

\section{Which Vision Best Suits Los Angeles?}

To answer this question, L.A. needs to know three things: what the community wants, what the arts infrastructure can support, and how L.A. compares with other cities and regions.

First, a vision for the future must inspire Los Angelenos with something they inherently see as valuable and desirable. Finding out what that is might involve canvassing groups with a stake and interest in the future of the arts and culture in Los Angeles, such as leaders of cultural institutions, neighborhood representatives, local volunteers, major patrons, and public officials in a variety of municipalities. Finding out what the community wants might also involve public surveys, opinion polls, focus groups, town hall meetings, and online discussions. Without an understanding of what the public and the arts community want to achieve, it could be difficult to align them behind a common vision and how it serves their goals.

Second, a vision for the future must have relevance and realism. Understanding the current context and its roots-demographically, economically, politically-is important to charting a realistic course for the future. In Arts and Culture in the Metropolis: Strategies for Sustainability, RAND researchers analyzed the relationship among three components of the local communities' arts ecology: their arts infrastructures; the support systems upon which they depend; and the sociodemographic, economic, and political environments in which they operate. This analysis helps communities assess their strengths and weaknesses and identify trends that define and challenge the health and sustainability of their arts sector. Understanding the assets and gaps in L.A.'s arts sector is a critical step for envisioning a realistic future.

Third, as any observer of adolescents knows, a sense of identity and a vision for what we want to be also comes from comparing ourselves with others. A vision gives the arts sector an identity and purpose that is distinctive from other sectors in the city (as well as from arts and other sectors in other cities). Los Angeles has many strengths to distinguish it among other major cities: a strong, creative arts infrastructure; the film and television industry; a tremendous number of artists; outstanding institutions of higher education for artists, designers, and related professionals; and impressive and diverse flagship organizations. On the other hand, L.A. lacks a sense of the region as a whole and a history of collaboration throughout the sector (though a new arts alliance and monthly funders meetings are positive signs). Different conditions lead cities to different visions and strategic approaches. How does L.A. stack up when compared with other key cities? What is L.A.'s niche?

Knowing these three things-what the community wants, what the arts infrastructure can support, and how we compare with other cities and regions-is critical to generating an inspiring yet realistic vision for the future that will make the most of L.A.'s unique cultural assets, guide arts and civic leaders in both good times and times of stress, and galvanize Los Angelenos. 


\section{Next Steps}

\section{These three items form an agenda for L.A.'s arts sector and for RAND.}

1 What the community wants. To begin to identify what Los Angelenos want, a series of meetings should be held to capture different perspectives throughout the region. These would include funders, arts organizations, artists, communitybased groups, the media, and others. In these discussions, Los Angelenos will be asked to think beyond the health of their particular institution or neighborhood and think about the future of the city and region as a whole. Where have we been? Where are we now? Where do we want to go? How do we get there?

2 What the arts infrastructure can support. A systematic analysis of the current state of the arts in Los Angeles along the lines of our research and recommendations in other major metropolitan regions needs to be conducted. In Philadelphia, for example, Arts and Culture in the Metropolis has framed the debate about strategies for sustainability of arts and culture of that city. The novel framework we created to advise Philadelphians is well-suited to an analysis of Los Angeles.

3 How Los Angeles compares with other cities. Our research would compare Los Angeles with other regions in terms of its history, current strengths and weaknesses, possible futures, and major challenges. While Los Angeles is unique in some regards-no other city has both world-class arts and entertainment plus the extraordinary demographics of Los Angeles-it can also benefit from the lessons of other major regions.

Ultimately, this agenda is motivated by the conviction that good information and objective analysis must inform the many conversations we need to have in Los Angeles about the arts over the years to come. Not research for the sake of research, but research to make a difference in the future of the region. Based on our initial look at Los Angeles as well as our research in other cities, we conclude with a few recommendations about how to proceed in our thinking about the future of the arts in L.A.:

- Think regionally, not just about the City of L.A. While acknowledging city, county, and the many municipal boundaries, do not be constrained by them in envisioning the future. Think about the health of the whole ecology.

- Consider the entire arts, culture, and entertainment sector, not just the nonprofit "high arts" or commercial industries. Also, include fashion, design, architecture, and new media to build on our strengths and synergies. There is too little collaboration at this time.

- Align the arts sector and its goals with broader community goals, such as education, neighborhood revitalization, and economic development. This is key to the ecological approach.

This is a time of real promise for Los Angeles, but also real challenge. To realize our full potential as a city and arts community, we have to know what we want and what we have to do to get there. Now is the time-while Los Angeles is on a roll-to look at these and other issues for the future of the arts in Los Angeles. That's what we at RAND-in conjunction with artists, arts leaders, funders, public officials, and others-hope to do.

RAND publications are available at www.rand.org

The RAND Corporation is a nonprofit research organization providing objective analysis and effective solutions that address the challenges facing the public and private sectors around the world. RAND's publications do not necessarily reflect the opinions of its research clients and sponsors. RAND ${ }^{\circledR}$ is a registered trademark. ๑ RAND 2007

\section{RAND Research in the Arts}

Since 2001, RAND has created a body of research shaping key issues; establishing analytic frameworks; and informing the policy debates about funding, government roles, education, and the value of the arts. Assessments of the performing, visual, and media arts are benchmarks in the field and Gifts of the Muse reoriented the debate about the benefits of the arts and arts advocacy. The "Vision for the Arts in L.A." Policy Forum in October 2006, the roundtable discussion in November 2006, and this publication reflect our desire to use this knowledge to have a positive impact in our own community.

A New Framework for Building Participation in the Arts (2001) http://www.rand.org/pubs/monograph_ reports/MR1323/

The Performing Arts in a New Era (2001) http://www.rand.org/pubs/monograph_ reports/MR1367/

From Celluloid to Cyberspace: The Media Arts and the Changing Arts World (2002) http://www.rand.org/pubs/monograph_ reports/MR1552/

Arts Education Partnerships: Lessons Learned from One School District's Experience (2004)

http://www.rand.org/pubs/monographs/ MG222/

Gifts of the Muse: Reframing the Debate About the Benefits of the Arts (2004) http://www.rand.org/pubs/monographs/ MG218/

State Arts Agencies, 1965-2003: Whose Interests to Serve? (2004)

http://www.rand.org/pubs/monographs/ MG121/

A Portrait of the Visual Arts: Meeting the Challenges of a New Era (2005) http://www.rand.org/pubs/monographs/ MG290/

The Arts and State Governments: At Arm's Length or Arm in Arm? (2006) http://www.rand.org/pubs/monographs/ MG359/

Arts and Culture in the Metropolis: Strategies for Sustainability (2007) http://www.rand.org/pubs/monographs/ MG477/

To learn more about RAND research in the arts, please visit www.rand.org/research areas/arts/.

If you are interested in an agenda for thinking about the future of the arts in Los Angeles, please contact Elizabeth Ondaatje (310.393.0411 x6767, ondaatje@rand.org) or Kevin McCarthy (310.393.0411 x6919, mac@rand.org). 